\title{
Cannabinoids Regulate the Diameter of Pericyte-Containing Retinal Capillaries in Rats
}

\author{
Yuan Zong ${ }^{a, c}$ Xujiao Zhou ${ }^{b, c}$ Jingyi Cheng ${ }^{a, c}$ Jian Yu ${ }^{a, c}$ Jihong Wu $u^{b, c}$ Chunhui Jiang ${ }^{a, c, d}$ \\ aDepartment of Ophthalmology and Vision Science, Eye and ENT Hospital, Fudan University, Shanghai, \\ ${ }^{\mathrm{b}}$ Eye and ENT Hospital, State Key laboratory of Medical Neurobiology, Institutes of Brain Science and \\ Collaborative Innovation Center for Brain Science, Fudan University, Shanghai, 'Key Laboratory of \\ Myopia of State Health Ministry, and Key Laboratory of Visual Impairment and Restoration of Shanghai, \\ Shanghai, ${ }^{d}$ Department of Ophthalmology, People's Hospital of Shanghai No. 5, Shanghai, People's \\ Republic of China
}

\section{Key Words}

Cannabinoid receptor type $1 \cdot$ Cannabinoid $\bullet$ Pericyte $\cdot$ Retinal capillary $\bullet$ Vasoregulation

\begin{abstract}
Background/Aims: Cannabinoids are vasoactive substances that act as key regulators of arterial tone in the blood vessels supplying peripheral tissues and the central nervous system. We therefore investigated the effect of cannabinoids on retinal capillaries and pericytes. Methods: The effects of cannabinoids on capillary diameters were determined using an ex vivo whole-mount rat retinal model. Western blotting, quantitative PCR, and immunohistochemistry were performed to explore the underlying mechanism. Results: Endogenous cannabinoid 2-arachidonoylglycerol and anandamide and exogenous cannabinoid (R-(+)-WIN55212-2) dilated the noradrenaline-precontracted capillaries in a concentration-dependent manner (1 $\mu \mathrm{M}$ to $0.1 \mathrm{mM}$ ). The extent of vasorelaxation was positively correlated with changes in pericyte width. The effects of R-(+)-WIN55212-2 on vasorelaxation and pericyte width were inhibited by a cannabinoid receptor type-1 (CB1) antagonist, AM251 or rimonabant (SR141716A), the nitric oxide synthase inhibitor L-NAME, and the guanylate cyclase inhibitor ODQ. They were also abolished by the removal of the endothelium, but not by the cannabinoid receptor- 2 antagonist SR144528, the endothelial cannabinoid receptor antagonist O-1918, or the cyclooxygenase inhibitor indomethacin. Conclusion: The exogenous cannabinoid R-(+)WIN55212-2 promotes the vasorelaxation of pericyte-containing rat retinal capillaries. This effect of R-(+)-WIN55212-2 is dependent on $\mathrm{CB}_{1}$ and the nitric oxide-cyclic guanosine monophosphate pathway, and requires an intact endothelium.
\end{abstract}




\section{Introduction}

The retinal vasculature is controlled by a highly responsive autoregulatory system with precise spatial and temporal modulation to meet the high nutrient demands. It is well established that pericyte-containing capillaries are important functional units involved in regulating tissue blood supply [1]. When the sensory input increases blood flow in vivo, capillaries dilate before the arterioles [2] and account for up to $84 \%$ of the increase in blood flow.

Previous studies have revealed that functional hyperemia is partly mediated by vasoactive substances [3, 4]. Several cannabinoids have been identified as vasoactive substances witch could dilated the mesenteric arteries in humans $[5,6]$, regulated the cerebrocortical blood flow [7] and dilate pulmonary artery in rats [8].

Endocannabinoids and their receptors are also extensively expressed in ocular tissues, which suggests that cannabinoids play important roles in the ocular system $[9,10]$. Previous studies have addressed the increasing neuroprotective and therapeutic potential of cannabinoids in systematic [11] and retinal disease [12-14], and several recent studies have evaluated the effects of cannabinoids on the ocular vascular system. Yu et al. reported that abnormal cannabidiol relaxed the resistant arterioles in the retina $[15,16]$. Romano et al. also reported the vasorelaxing effect of anandamide and WIN55212-2 on the bovine ophthalmic artery [17]. However, the effects of cannabinoids on the retinal capillaries have yet to be determined.

Therefore, the aim of the present study was to determine the biological effects of cannabinoids on retinal capillaries using a live whole-mount, buffer-perfused rat retina model. Understanding the pharmacological effects of cannabinoids on retinal capillaries should provide further insight into the regulation of retinal vessel tone.

\section{Materials and Methods}

\section{Animals}

The animal protocols in the study conformed to the European Convention for the Protection of Vertebrate Animals used for Experimental Research and the Guidelines of Fudan University on the Ethical Use of Animals. Adult male Wistar rats (200-250 g) were purchased from SLAC Laboratory Animal Co., Ltd, Shanghai, China. The rats were maintained in an automatic rhythmic day-night environment at a room temperature of $22 \pm 2{ }^{\circ} \mathrm{C}$ and $50 \%$ humidity. The rats had free access to water and food.

\section{Whole-mount preparation and imaging}

The rats were killed with an intraperitoneal injection of $20 \%$ chloral hydrate and the eyes were enucleated. After hemisection of the eyes along the ora serratae, the cornea, lens, and vitreous body were removed. The entire retina was gently peeled away and the vitreous humor was removed from the retinal pieces by gentle peeling with forceps under a dissecting microscope. The retinas were transferred to a dissecting dish containing prewarmed $\left(37^{\circ} \mathrm{C}\right)$, oxygenated $\left(95 \% \mathrm{O}_{2}+5 \% \mathrm{CO}_{2}\right)$ artificial cerebrospinal fluid (ACSF) containing (in mM): $\mathrm{NaCl} 125, \mathrm{KCl} 3, \mathrm{NaHCO}_{3} 26, \mathrm{NaH}_{2} \mathrm{PO}_{4} 1.25$, glucose 15, $\mathrm{CaCl}_{2} 2$, and $\mathrm{MgCl}_{2} 1(\mathrm{pH}$ 7.4). The retinas were then divided into four quadrants and mounted whole, vitreous side up. The individual retinas were then transferred to a recording-chamber bath mounted on the stage of an upright microscope and covered with a nylon mesh and a tungsten wire ring. The retinas were continuously superfused with 2-3 $\mathrm{mL} \mathrm{min}^{-1}$ with oxygenated ACSF at $37^{\circ} \mathrm{C}$. Capillaries were defined as vessels of $<10 \mu \mathrm{m}$ in diameter that lack a continuous layer of smooth muscle $[2,18]$. Within the whole-mount retinal preparations, the capillaries were visualized with infrared differential interference contrast (IR-DIC) microscopy using a waterimmersion objective lens at a magnification of $40 \times$. IR-DIC images of pericytes in the retinal capillaries were identified by their 'bump on a log' morphology [18], seen in confocal images of anti- neural/glial antigen-2 (NG 2)-labeled pericytes (Fig. 1). The capillary diameter was measured as previously reported [19]. For each retinal sample, the capillary diameter was measured at the same end of the same pericyte after each procedure to ensure the measurements were made in the same position. The soma width of the same 


\section{Cellular Physiology Cell Physiol Biochem 2017;43:2088-2101 \begin{tabular}{l|l|l} 
and Biochemistry $10.1159 / 000484193$ & $\begin{array}{l}\text { C) } 2017 \text { The Author(s). Published by S. Karger AG, Basel } \\
\text { www.karger.com/cpb }\end{array}$ \\
\hline
\end{tabular}}

Zong et al.: Cannabinoids Affect Retinal Capillaries

pericyte was also measured in each sample. To compare capillaries between pericyte sites and non-pericyte sites, the capillary diameters were also measured at the sites of the pericyte somas and at non-pericyte sites.

\section{Experimental protocols}

Because the whole retinal mounts lacked myogenic tone, the capillaries in which the intact endothelium or endothelium was denuded were precontracted with noradrenaline (NA) to assess the vasodilator response to the test drugs. After a stable level (the capillary diameter did not change for $5 \mathrm{~min}$ ) of precontraction had been achieved, the test drugs were applied to the whole mounts in the continued presence of NA. All antagonists were perfused for $30 \mathrm{~min}$ before the subsequent experiment.

Only one capillary was examined in each whole-mount retinal sample with a maximum of two capillaries from each animal (one from each eye). At least three animals (six capillaries from six samples) were used in each experimental protocol. When the capillaries showed a change of more than $25 \%$ of the initial vessel diameter in response to NA, we regarded the contractility of the vessels to be similar (because $23.9 \%$ was twice the standard deviation of the average baseline vessel diameter over all the vessels studied). When we examined the concentration dependence of the response, the concentration ranges were $10^{-8} \mathrm{M}$ to $10^{-3} \mathrm{M}$ for NA, and $10^{-6} \mathrm{M}$ to $10^{-4} \mathrm{M}$ for 2-arachidonoylglycerol (2-AG), anandamide (AEA) and R-(+)-WIN55212-2; these concentrations were also used in other studies [20-22].

\section{Vessel isolation}

The retinas were rapidly removed from the eyes as described above and incubated in $2.5 \mathrm{ml}$ of Earle's balanced salt solution supplemented with $6 \mathrm{U}$ of papain (Sigma, Munich, Germany) for $25-30 \mathrm{~min}$ at $30{ }^{\circ} \mathrm{C}$ [23]. The retinal vessels were then carefully isolated using $0.1 \mathrm{~mm}$ microforceps under a surgical microscope (Type SOM2000D, 66 Vision Tech. Co., China).

\section{Western blotting}

The retina was homogenized in cell lysis buffer containing protease inhibitor cocktail. The homogenate was centrifuged at $12,000 \times g$ for $10 \mathrm{~min}$ at $4{ }^{\circ} \mathrm{C}$. The supernatant was removed and the protein concentration was determined using a bicinchoninic acid protein assay. The samples were separated by electrophoresis on a $10 \%$ running. Tris-glycine acrylamide gel and then transferred to a polyvinylidene difluoride membrane and blocked with 5\% milk. After blocking, the membranes were washed three times with phosphate-buffered saline (PBS) and incubated for $1 \mathrm{~h}$ at room temperature. They were then incubated overnight at $4{ }^{\circ} \mathrm{C}$ with the primary antibody, rabbit anti-cannabinoid receptor type $1\left(\mathrm{CB}_{1}\right.$ ) (diluted 1:1000; ab172970, Abcam Inc., Cambridge, MA, USA). The membranes were then washed with PBS and incubated with the appropriate secondary antibody, horseradish-peroxidase-conjugated goat anti-rabbit IgG antibody (1:4000; sc-2004, Santa Cruz, Biotechnology, CA, USA). Immunoreactivity was visualized with an enhanced chemiluminescence kit. The relative intensities of the protein bands were quantified by scanning densitometry using Image J software (National Institutes of Health, USA). Tubulin was used as the internal standard. The density of the bands was normalized for the expression of tubulin and then to the expression in control eyes.

\section{Quantitative PCR}

RNA was extracted from the intact retina and the retinal vasculature using a previously described protocol [24]. Briefly, the vasculature was added to $1 \mathrm{ml}$ of TRIzol Reagent (Invitrogen Canada Inc., Burlington, ON, Canada). After tissue homogenization, $200 \mu \mathrm{L}$ of chloroform was added to each sample. The homogenate was then mixed vigorously for $15 \mathrm{~s}$, incubated for $3 \mathrm{~min}$ on ice and centrifuged at $12,000 \times g$ for $10 \mathrm{~min}$. The aqueous phase was transferred to a new microcentrifuge tube and $500 \mu \mathrm{L}$ of isopropanol was added. The solution was mixed, placed on ice for $15 \mathrm{~min}$, and then centrifuged at $12,000 \times g$ for 15 min at $4{ }^{\circ} \mathrm{C}$. The supernatant was then removed and the RNA pellet was washed twice with $1.0 \mathrm{~mL}$ of $75 \%$ ethanol, vortexed, and centrifuged at $7500 \times g$ for $5 \mathrm{~min}$ at $4{ }^{\circ} \mathrm{C}$. The RNA pellet was then allowed to air dry for approximately $10 \mathrm{~min}$ and was suspended in $\mathrm{ddH}_{2} \mathrm{O}$. The purity and concentration of the collected RNA were determined by measuring the $\mathrm{A}_{260} /{ }_{280}$ absorbance ratio of each sample. The RNA samples were stored at $-80{ }^{\circ} \mathrm{C}$ until use. The primer sequences for $\mathrm{CB}_{1}$ were $5^{\prime}$-CACTCTGGCATCAGGGTTATC-3' (forward) and 5'-CATCTGGTAGTTGGGCCTATTT-3' (reverse). The PCR cycling parameters were: $95{ }^{\circ} \mathrm{C}$ for $7 \mathrm{~min}$, followed by 40 cycles of $94{ }^{\circ} \mathrm{C}$ for $30 \mathrm{~s}, 55^{\circ} \mathrm{C}$ for $30 \mathrm{~s}$, and $72{ }^{\circ} \mathrm{C}$ for $30 \mathrm{~s}$. Real-time PCRs were performed with the ViiA 7 Real-Time PCR system (Applied Biosystems, Inc., Foster City, CA, USA). GAPDH was used as the control 


\section{Cellular Physiology Cell Physiol Biochem 2017;43:2088-2101 \begin{tabular}{l|l|l} 
and BOI: 10.1159/000484193 & $\begin{array}{l}\text { (c) } 2017 \text { The Author(s). Published by S. Karger AG, Basel } \\
\text { www.karger.com/cpb }\end{array}$
\end{tabular} \\ Zong et al.: Cannabinoids Affect Retinal Capillaries}

housekeeping gene. The relative changes in the target gene expression were normalized using the $2^{-\triangle \Delta C T}$ method and the results are expressed as the fold difference relative to GAPDH.

\section{Immunohistochemistry}

The whole-mount retina was fixed in 4\% paraformaldehyde for $30 \mathrm{~min}$ and washed three times in PBS for 5 min each. After fixation, the retina was incubated in $0.5 \%$ Triton X-100 in PBS for 40 min and blocked with $3 \%$ bovine serum albumin (BSA) in PBS for $1 \mathrm{~h}$ at room temperature. $\mathrm{CB}_{1}$ and neural/glial antigen 2

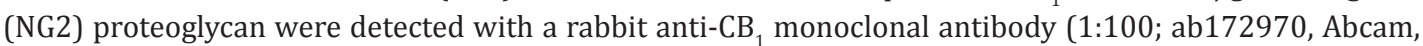
Cambridge, MA, USA) and mouse anti-NG2 monoclonal antibody (1:200; ab50009, Abcam, Cambridge, MA, USA) for 1 day at $4{ }^{\circ} \mathrm{C}$. The following secondary antibodies were used: 555-conjugated donkey antirabbit IgG antibody (1:1000; A31572, Invitrogen Molecular Probes, Eugene, OR, USA), 555-conjugated goat anti-mouse IgG antibody (1:1000; A28180, Invitrogen Molecular Probes), 488-conjugated goat anti-rabbit IgG antibody (1:500; A11070, Invitrogen Molecular Probes). The secondary antibodies were applied for $1 \mathrm{~h}$ at room temperature. The retinas were incubated with Alexa-Fluor-488-conjugated isolectin B4 (IB4; Invitrogen, Paisley, UK) to detect the retinal capillaries. IB4 $\left(20 \mu \mathrm{g} \mathrm{mL}^{-1}\right)$ was prepared in PBS. Some of the retina was counterstained with the nucleic acid stain Hoechst 33258 (1:2000, H3569, Invitrogen Molecular Probes) in PBS as needed. The retinas were then incubated with IB4 for 45 min and examined under a Leica TCS SP8 confocal microscope (Leica Microsystems, Heidelberg, Germany) with a 63× water immersion objective lens. The images were assembled in Adobe Photoshop version 7.0 (Adobe Systems, San Jose, CA, USA).

\section{Drugs}

(R)-(+)-[2, 3-Dihydro-5-methyl-3-(4-morpholinylmethyl)pyrrolo $\quad[1, \quad 2,3-d e]-1, \quad 4$-benzoxazin6-yl]-1-naphthalenylmethanonemesylate $\quad((\mathrm{R})-(+)-[W I N 55, \quad 212-2, \quad 10 \mu \mathrm{M}), \quad(5 Z, 8 Z, 11 Z, 14 Z)-N-(2-$ hydroxyethyl)icosa-5, 8,11, 14-tetraenamide (AEA, $10 \mu \mathrm{M})$, 1, 3-dihydroxy-2-propanyl (5Z,8Z,11Z,14Z)-5, 8,11, 14-eicosatetraenoate (2-AG, $10 \mu \mathrm{M}), 1 \mathrm{H}-[1,2,4]$ oxadiazolo [4, 3-a]quinoxalin-1-one (ODQ 10 $\mu \mathrm{M})$, 3-[(3-cholamidopropyl)dimethylammonio]-1-propanesulfonate (CHAPS, 0.3\%), NA (2 $\mu \mathrm{M})$, papain, dimethyl sulfoxide (DMSO), and BSA were purchased from Sigma Aldrich (St. Louis, MO, USA). 5-(4-Chlorophenyl)-1-(2, 4-dichloro-phenyl)-4-methyl-N- (piperidin-1-yl)-1H-pyrazole-3-carboxamide (rimonabant, $10 \mu \mathrm{M}$ ), $\quad N$-(piperidin-1-yl)-5-(4-iodophenyl)-1-(2, 4-dichlorophenyl)-4-methyl-1Hpyrazole-3-carboxamide (AM251, $1 \mu \mathrm{M}$ ), 5-(4-chloro-3-methylphenyl)-1-[(4-methylphenyl)methyl]-N[(1S,2S,4R)-1, 3,3-trimethylbicyclo [2.2.1]heptan-2-yl]-1H-pyrazole-3-carboxamide (SR144528, $10 \mu \mathrm{M})$, and 1, 3-dimethoxy-5-methyl-2-[(1R,6R)-3-methyl-6-(1-methylethenyl)-2-cyclohexen-1-yl]-benzene (01918, $10 \mu \mathrm{M}$ ) were purchased from Cayman Chemicals Company (Ann Arbor, MI, USA). Antagonists were administered before WIN55, 212-2. L-NG-Nitroarginine methyl ester (L-NAME, $100 \mu \mathrm{M}$ ) and indomethacin $(10 \mu \mathrm{M})$ were purchased from Selleck Chemicals (Houston, TX, USA). WIN55, 212-2, 2-AG, ODQ, 0-1918, AM251, and rimonabant were dissolved in DMSO. AEA, SR144528, and indomethacin were dissolved in ethanol. NA, L-NAME, and CHAPS were dissolved in deionized water. All compounds were diluted to the desired final concentrations with deionized water.

\section{Statistics}

All data are normalized vessel diameter percentages, are given as the percentage change in the vessel diameter relative to the diameter before the administration of any drug and are presented as mean \pm standard errors of the means (SEM). The significance of the concentration-dependent responses was compared using one-way ANOVA, and the maximal responses (Rmax) were compared with paired $t$ tests. The median excitatory concentration $\left(\mathrm{EC}_{50}\right)$ was calculated with the Origin 6.0 software (Originlab, Northampton, MA). One-way ANOVA was also used to compare the results of multiple treatments, followed by Bonferroni's multiple-comparison test. A linear regression analysis was performed to determine the correlation between pericyte width and the change in vessel diameter. $P$ values of $<0.05$ were considered statistically significant.

\section{Results}

The mean diameter of the capillaries was $5.05 \pm 0.61 \mu \mathrm{m}$. The capillary diameter was extremely stable over a 60-min period when perfused with ACSF without the addition of 


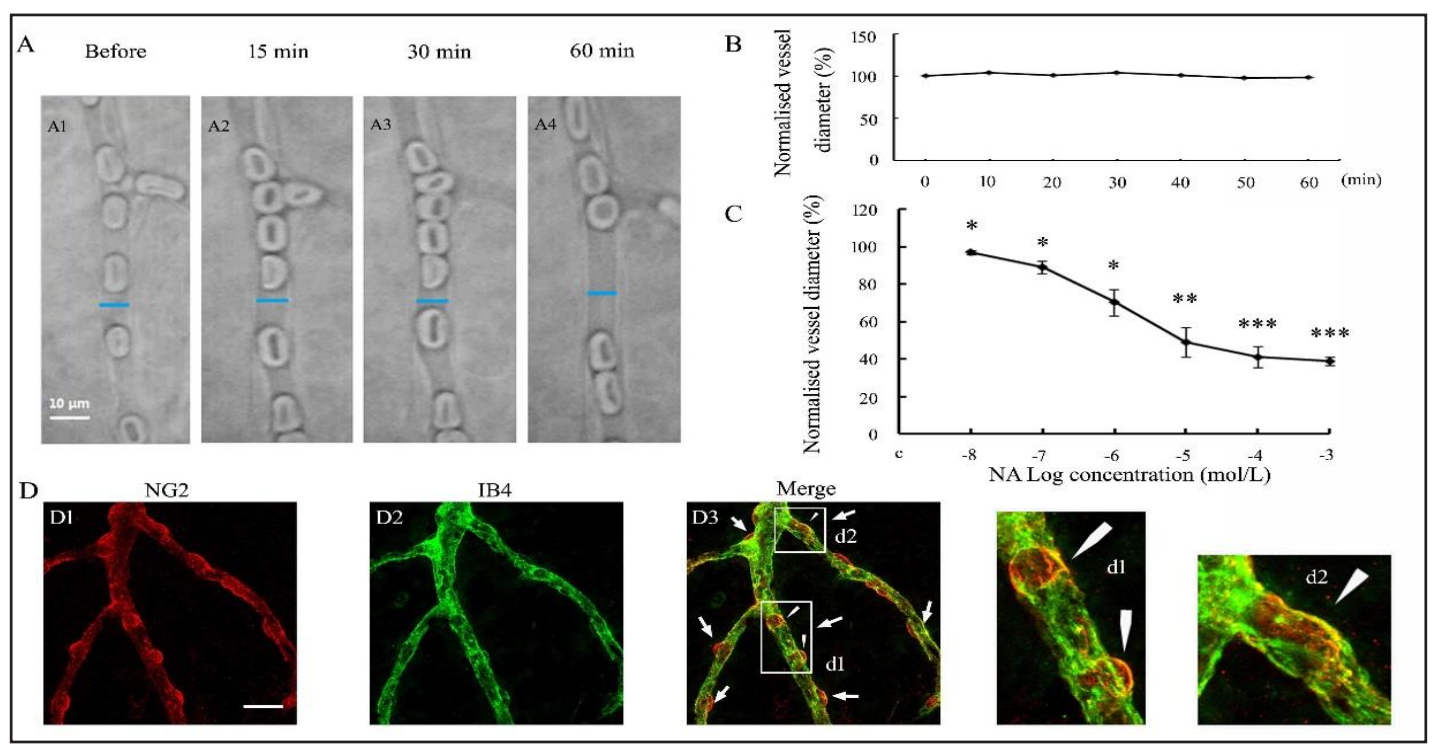

Fig. 1. General describing.(A, B) Images and summarized data of capillaries from a perfused whole-mount rat retinas over a 60-min period in the absence of any drug. (C) Concentration-dependent effects of NA on vasoconstriction of retinal capillaries $(n=6)$. (D) Confocal microphotographs of pericytes labeled with antiNG2 antibody (D1, arrowheads in D3) and capillaries labeled with IB4 (D2). (D3) Merged images. Scale bars, $20 \mu \mathrm{m}$. (d1, d2) Magnification of the inset in D3. ${ }^{*} \mathrm{P}<0.05$, ${ }^{*} \mathrm{P}<0.01$ and ${ }^{* *} \mathrm{P}<0.001$. IB4, isolectin B4; NA, noradrenalin; NG2, neural/glial antigen 2.

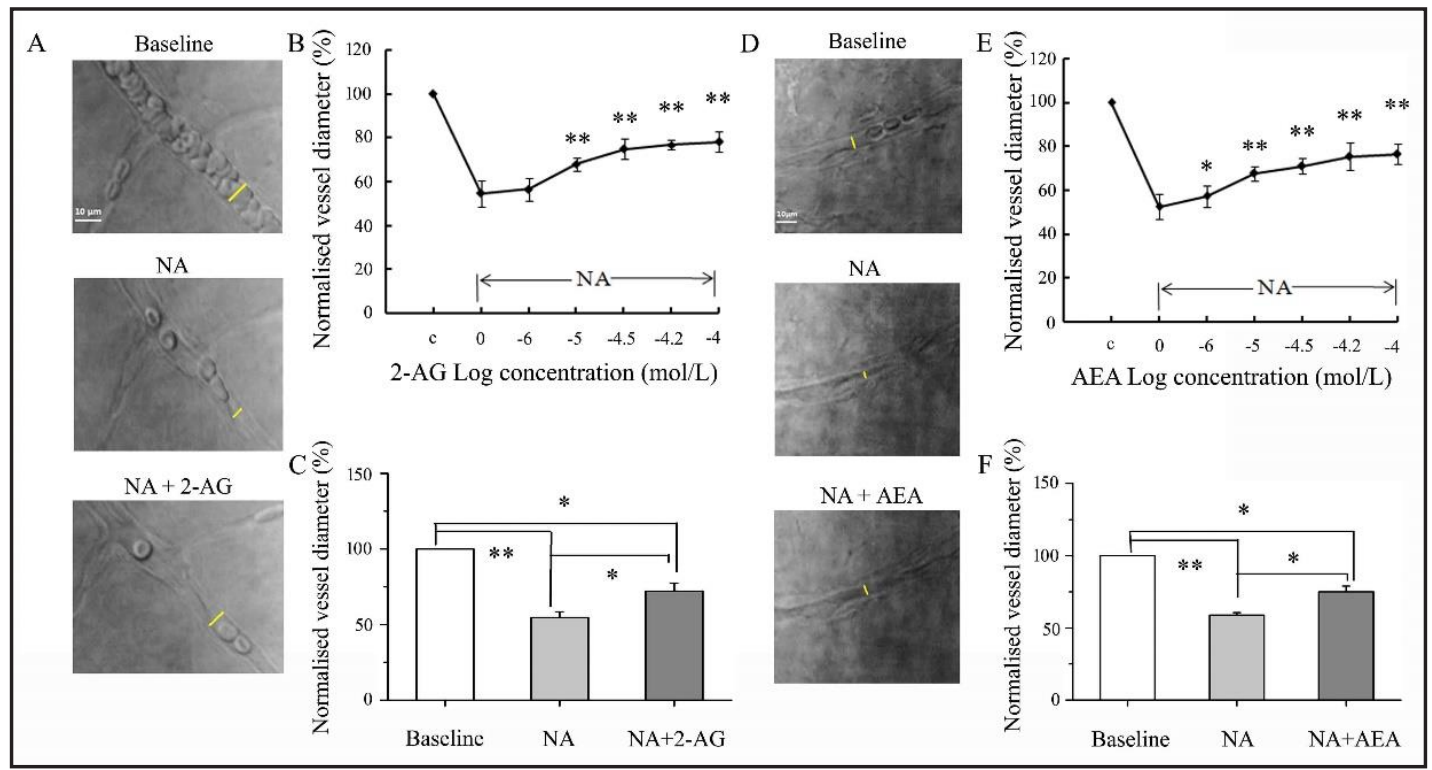

Fig. 2. Effects of endocannabinoids on NA-precontracted retinal capillaries.(A, C) Images and summarized data of percent change in retinal capillary diameter on condition of NA, NA+2-AG perfusion $(n=7)$. (D, F) Images and summarized data of percentage change in the retinal capillary diameter after NA or NA+2-AG perfusion $(n=6)$. (B, E) 2-AG or AEA caused concentration-dependent dilation of NA-precontracted capillaries (both $\mathrm{n}=6$ ). ${ }^{*} \mathrm{P}<0.05,{ }^{*} \mathrm{P}<0.01$ and ${ }^{* *} \mathrm{P}<0.001$. 2-AG, 2-arachidonylglycerol; $\mathrm{AEA}$, anandamide; Con, control; The yellow lines in $\mathrm{A}$ and $\mathrm{D}$ indicate the lumen diameter.

any drug (Fig. 1A, B). NA was used to precontract the capillaries. The contractile effect of NA was concentration dependent, and was significant at concentrations of $\geq 10 \mathrm{nM}(P<0.05$ vs baseline), reaching a maximum value of $60.18 \pm 1.51 \%$ at a concentration of $1 \mathrm{mM}(P<0.001$ 


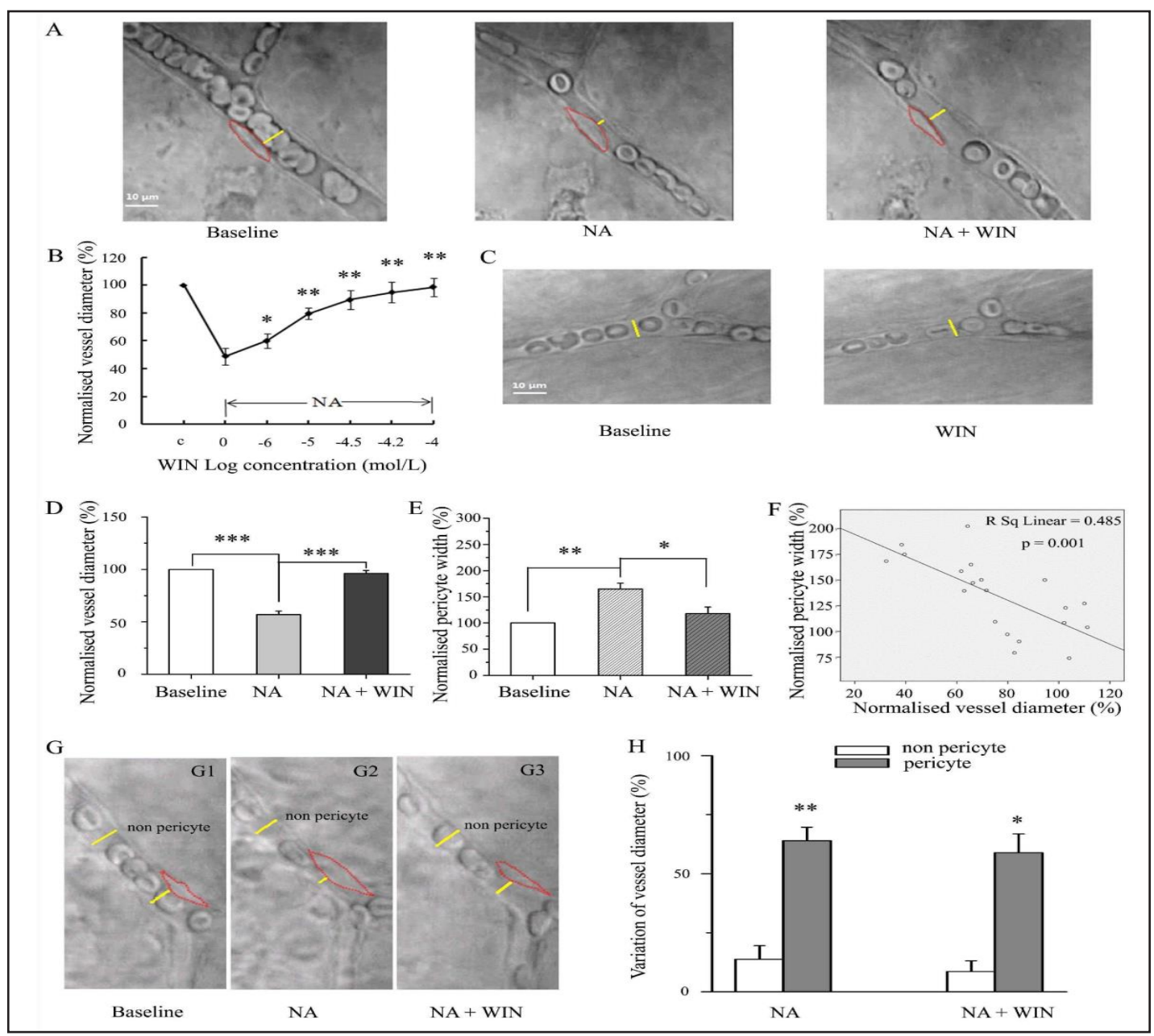

Fig. 3. Effects of R-(+)-WIN55212-2 on NA-precontracted retinal capillaries and pericytes. (A) Images of capillary showing R-(+)-WIN55212-2-induced vasodilation. (B) R-(+)-WIN55212-2 caused concentrationdependent dilation of NA-precontracted capillaries $(n=6)$. (C) Images showing R- $(+)$-WIN55212-2 induced effect on non-precontracted capillaries. (D, E) Summarized data of percentage changes in retinal capillary diameter and pericyte width induced by NA or NA + R-(+)-WIN55212-2 ( $\mathrm{n}=12)$. (F) Linear regression analysis for correlation between capillary diameter and change in pericyte width. (G, H) Images and quantitative analysis showing pericyte width and retinal capillary diameter variations measured at pericyte sites and non-pericyte sites. $(\mathrm{n}=10) .{ }^{*} \mathrm{P}<0.05,{ }^{* *} \mathrm{P}<0.01$, and ${ }^{* * *} \mathrm{P}<0.001$. Con, control; NA, noradrenalin; WIN, R-(+)-WIN55212-2. The yellow lines in A, C and G indicate the lumen diameter. The red circles in A and G indicate the outlines of pericytes.

vs baseline; Fig. 1C). The $\mathrm{EC}_{50}$ was $1.57 \pm 0.23 \mu \mathrm{M}$, and $2 \mu \mathrm{M}$ NA was selected for subsequent experiments. Three whole-mount retinal samples were excluded because the contraction of the capillaries induced by $2 \mu \mathrm{M}$ NA was $<25 \%$. This concentration of NA reduced the basal capillary diameter by $43.09 \pm 3.31 \%(P<0.001$ vs baseline, $\mathrm{n}=25$; Fig. $3 \mathrm{~A}$, D) and increased the basal pericyte width by a mean of $64.9 \pm 11.0 \%(P<0.01$ vs baseline, $\mathrm{n}=12$; Fig. 3A, E). The effect of NA on the capillary diameter was greater at pericyte soma sites than at nonpericyte sites $(63.96 \pm 5.71$ vs $13.74 \pm 5.82 \%, P<0.01$; Fig. $3 \mathrm{G}, \mathrm{H})$. Confocal images of antiNG2-labeled pericytes were used to determine the mean distance between pericyte somas along retinal capillaries $(14.4 \pm 1.23 \mu \mathrm{m}, \mathrm{n}=18)$ and the density of pericytes $(7.25 \pm 0.48$ pericytes per $100 \mu \mathrm{m}^{2}(\mathrm{n}=18$, Fig. 1D). 
Fig. 4. Signaling system of R-(+)WIN55212-2-induced vasodilation. (A-D) Effects of the rimonabant (SR141716A, $n=6$ ) or AM $251(n=6)$, the SR144528 ( $\mathrm{n}=7$ ), or 0-1918 ( $\mathrm{n}=6)$ on R(+)-WIN55212-2-induced vasodilation. (E) Effects of endothelial denudation $(\mathrm{n}=6)$ on R - ( + ) - W I N 55212 2 -induced vasodilation $(\mathrm{n}=6) \cdot(\mathrm{F}-\mathrm{H})$ Effects of L-NAME ( $\mathrm{n}=6)$, ODQ ( $\mathrm{n}=8)$, or indomethacin ( $\mathrm{n}=8$ ) on R-(+)-WIN55212-2-induced vasodilation. (I) Comparison of R-(+)WIN55212-2-induced dilation (control) in the absence or presence of antagonists, inhibitors, or endothelial denudation. ${ }^{* *} \mathrm{P}<0.01$ and $* * * \mathrm{P}<0.001$. NA, noradrenalin; WIN, R-(+)-WIN55212-2; CHAPS, 3-[(3-chol-

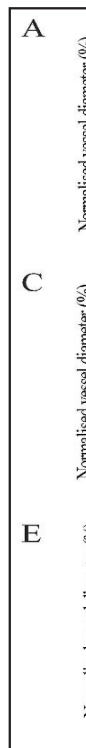

G

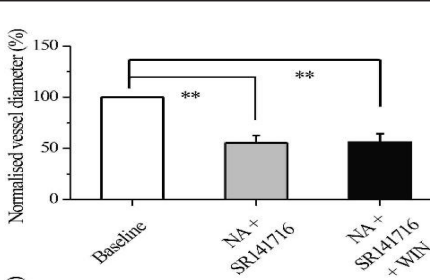

C
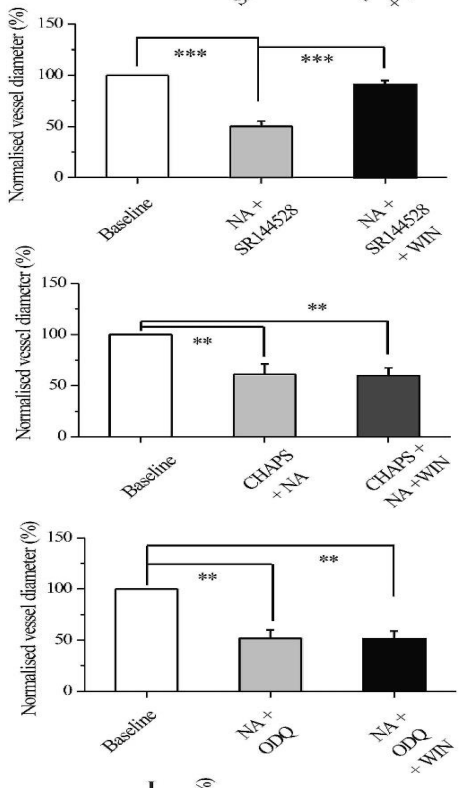

I
B

D

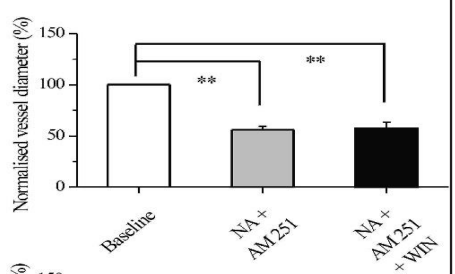

F

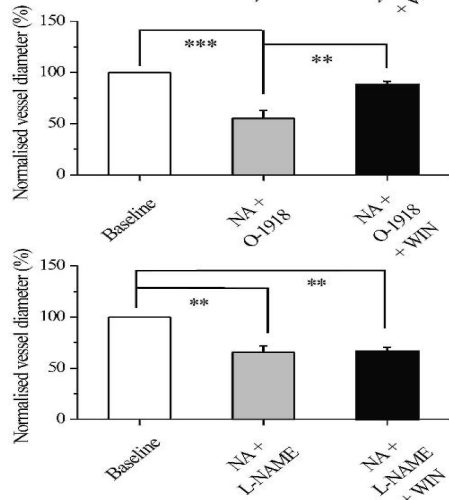

$\mathrm{H}$

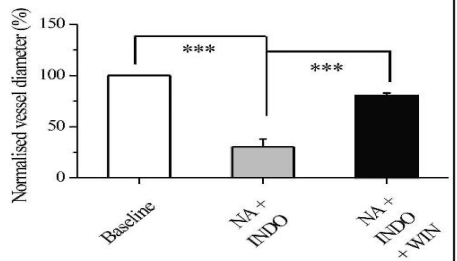

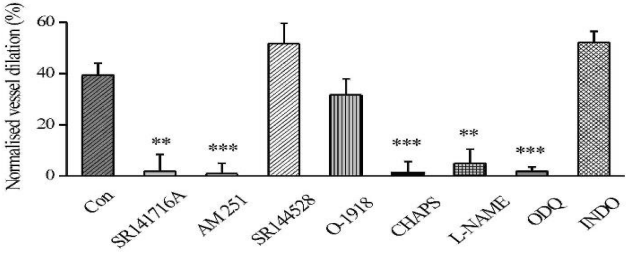

a m i d o p r o p y l)

dimethylammonio]-1-propanesulfonate; L-NAME, L-NG-nitroarginine methyl ester; ODQ 1H-[1,2,4] oxadiazolo[4,3-a]quinoxalin-1-one; INDO, indomethacin; Con, control.

\section{Effects of endocannabinoids on NA-precontracted retinal capillaries}

The effects of the endocannabinoids 2-AG and AEA and the exogenous cannabinoid R-(+)-WIN55212-2 on NA-precontracted capillaries with intact endothelia were tested. 2-AG and AEA caused a concentration-dependent relaxation of the NA-precontracted capillaries (Fig. 2B, E); The $\mathrm{EC}_{50}$ was each $8.50 \pm 0.36 \mu \mathrm{M}$ for $2-\mathrm{AG}$ and $12.47 \pm 5.1 \mu \mathrm{M}$ for AEA, so they were used at concentrations of $10 \mu \mathrm{M}$ in our study. 2-AG $(10 \mu \mathrm{M})$ and AEA $(10 \mu \mathrm{M})$ caused the relaxation of the precontracted retinal capillaries (2-AG: $17.53 \pm 1.96 \%$; AEA: $16.11 \pm 2.36 \%$; all $P<0.05$; Fig. $2 \mathrm{~A}, \mathrm{C}, \mathrm{D}, \mathrm{F})$ relative to the NA-precontracted capillaries. However, 2-AG and AEA were significantly less potent (all $P<0.05 v s$ R-(+)-WIN55212-2) than R-(+)-WIN55212-2 (10 $\mu \mathrm{M})(39.38 \pm 4.62 \%, P<0.001$ vs NA-precontracted vessels; Fig. $3 \mathrm{~A}, \mathrm{D})$. Therefore, R-(+)-WIN55212-2 was used in subsequent experiments. In the control experiments, vehicle alone $(0.1 \%$ DMSO or ethanol, the concentrations used in this study) did not significantly affect vessel tone.

Effects of R-(+)-WIN55212-2 on NA-precontracted retinal capillaries and pericytes

R-(+)-WIN55212-2 caused the relaxation of NA-precontracted capillaries with intact endothelia in a concentration-dependent manner (Fig. 3B), but did not affect non- 
Fig. 5. Signaling system of R-(+)WIN 55212 2 - in d u c e d pericyte variation. (A-D) Effects of the rimonabant (SR141716A, $\mathrm{n}=6), \mathrm{AM}$ 251 ( $\mathrm{n}=6$ ), the SR144528 (n = 7), or 0-1918 (n = 6) on R-(+)WIN 55212 2 - in d u c e d pericyte variation. (E-G) Effects of $\mathrm{L}^{-}$ NAME $(\mathrm{n}=$ 6), ODQ ( $\mathrm{n}=$ $8)$, or indomethacin (n = 8) on R-(+)WIN 55212 2 - in d u c e d p e r i c y t e variation. (H) Comparison of R-(+)WIN55212-2 (control)-induced pericyte variation in the absence or presence of antagonists or inhibitors. ${ }^{*} \mathrm{P}<0.05$, ${ }^{* *} \mathrm{P}<0.01$ and ${ }^{* * *} \mathrm{P}<0.001$. NA, noradrenalin; WIN, R-(+)-WIN55212-2; L-NAME, L-NG-nitroarginine methyl ester; ODQ 1H-[1,2,4] oxadiazolo[4,3-a]quinoxalin-1-one; INDO, indomethacin; Con, control.

precontracted capillaries (Fig. 3C). This relaxation was significant at concentrations $\geq 1 \mu \mathrm{M}$ (all $P<0.05$ vs NA-precontracted vessels), reaching a maximum vasorelaxation of $50.08 \pm$ $6.8 \%$ at a concentration of $100 \mu \mathrm{M}(P<0.001)$. The $\mathrm{EC}_{50}$ was $9.57 \pm 0.72 \mu \mathrm{M}$, so $10 \mu \mathrm{M} \mathrm{R}-(+)-$ WIN55212-2 was used in subsequent experiments. R-(+)-WIN55212-2 $(10 \mu \mathrm{M})$ increased the diameter of the NA-precontracted capillaries by $39.38 \pm 4.69 \%(P<0.001$; Fig. 3A, D) and reduced the pericyte width by $46.97 \pm 10.13 \%(P<0.05$; Fig. 3A, E). Linear regression revealed a significant correlation between the percentage change in capillary diameter and pericyte width $\left(P<0.01, \mathrm{R}^{2}=0.485\right.$; Fig. $\left.3 \mathrm{~F}\right)$. Capillary dilation was significantly greater at pericyte soma sites than at non-pericyte sites $(58.86 \pm 7.99 \%$ vs $8.54 \pm 4.63 \%$, respectively; $P<0.05$; Fig. 3G, H).

\section{Signaling pathway of R-(+)-WIN55212-2-induced relaxation of retinal capillaries}

In capillaries with intact endothelia, pretreatment with the $\mathrm{CB}_{1}$ antagonist rimonabant $(10 \mu \mathrm{M})[25]$ or AM251 $(1 \mu \mathrm{M})[26]$ inhibited their vasorelaxation (rimonabant: $P<0.01 v s$ Control, Fig. 4A, I; AM251: $P<0.001$ vs Control, Fig. 4B, I) and the change in pericyte width (both $P<0.05$ vs Control; Fig. 5A, B, H). By contrast, pretreatment with the $\mathrm{CB}_{2}$ antagonist SR144528 $(10 \mu \mathrm{M})$ [27] did not inhibit the effects of R-(+)-WIN55212-2 (capillary diameter and pericyte width: $P>0.05$ vs Control; Fig. 4C, I, Fig. 5C, H). The same result was seen when 


\section{Cellular Physiology Cell Physiol Biochem 2017;43:2088-2101

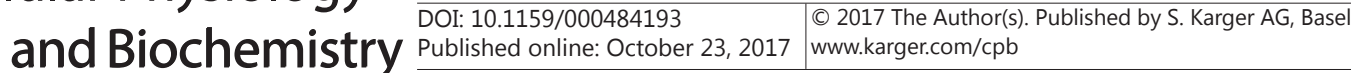

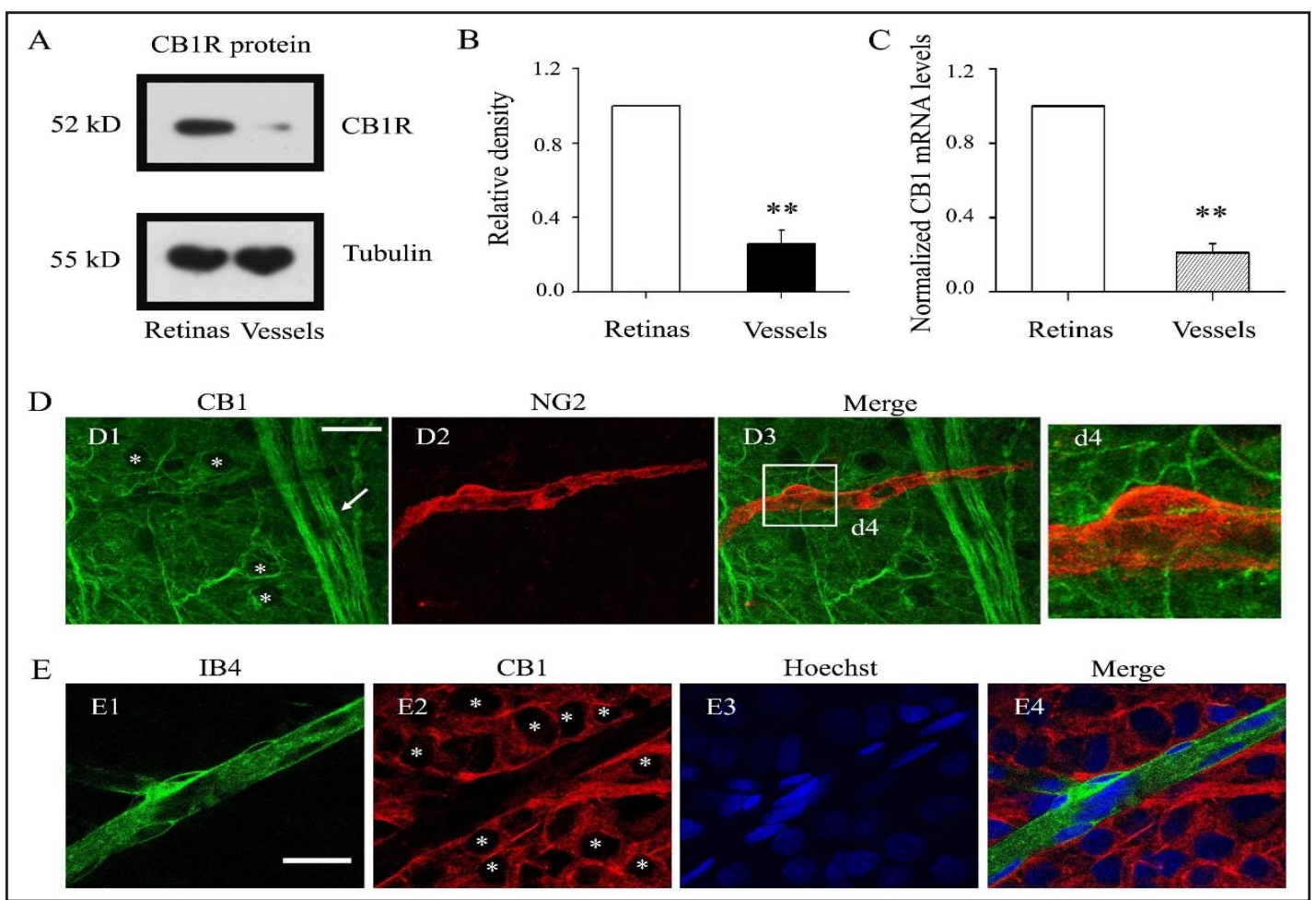

Fig. 6. Cannabinoid receptor type $1\left(\mathrm{CB}_{1}\right)$ expression in the retina. $(\mathrm{A})$ Western blots of $\mathrm{CB}_{1}$ protein expression in the retina and retinal vessels. $(B)$ Densitometric analysis of $\mathrm{CB}_{1}$ protein expression in the retina and retinal vessels. Different protein levels were normalized to the level of $\beta$-tubulin. (C) Real-time PCR analysis of $\mathrm{CB}_{1}$ mRNA relative to GAPDH mRNA. Results are shown as means \pm standard errors. (D) Immunofluorescent labeling of $\mathrm{CB}_{1}$ protein (D1, green) in the rat whole-mount retina. (D2) NG2-labeled images (red). (D3) Merged images. (d4) Magnification of the inset in D3. (E) Confocal images of rat whole-mount retina stained for IB4 (E1, green), $\mathrm{CB}_{1}$ (E2, red), and Hoechst (E3, blue). (E4) Merged image. Scale bars, $20 \mu$ m. *Retinal ganglion cells. Arrow: ganglion cell axons. IB4, isolectin B4; NG2, neural/glial antigen 2.

the endothelial cannabinoid receptor antagonist 0-1918 $(10 \mu \mathrm{M})$ [26] was used (capillary diameter and pericyte width: $P>0.05$ vs Control; Fig. 4D, I, Fig. 5D, H).

To test whether the R-(+)-WIN55212-2-induced vasodilatory response was dependent on the endothelium, the endothelium was chemically denuded with CHAPS (0.3\%) [16]. Preincubation with CHAPS did not significantly affect the diameter of the non-precontracted capillaries $(P>0.05$ vs endothelium intact vessels $)$ or NA-precontracted capillaries $(P>0.05$ $v s$ endothelium-intact vessels; Fig. 4E). Pretreatment with CHAPS significantly reduced the vasodilatory effects of R-(+)-WIN55212-2 ( $P>0.05$ vs NA-precontracted vessels; $P<0.001$ vs control; Fig. 4E, I).

In capillaries with intact endothelia, pretreatment with L-NAME $(100 \mu \mathrm{M})$ [28], a nitric oxide synthase (NOS) inhibitor, or ODQ $(10 \mu \mathrm{M})$ [29], a selective guanylyl cyclase (GC) blocker, significantly blocked the action of R-(+)-WIN55212-2 on NA-precontracted capillaries (L-NAME: $P<0.01$ vs Control, Fig. 4F, I; ODQ: $P<0.001$ vs Control, Fig. 4G, I) and pericytes (both $P<0.05$ vs Control;, Fig. 5E, F, H). By contrast, pretreatment with indomethacin (10 $\mu \mathrm{M})[26]$, an inhibitor of cyclooxygenase (COX) activity, did not affect R-(+)-WIN55212-2induced vasorelaxation $(P>0.05$ vs Control; Fig. $4 \mathrm{H}, \mathrm{I})$ or the changes in pericyte width $(P>$ 0.05 vs Control; Fig. 5G, H).

None of the antagonists had any effect on the basal tone of the retinal capillaries in the 30 min after its application.

\section{KARGER}




\section{Cellular Physiology Cell Physiol Biochem 2017;43:2088-2101

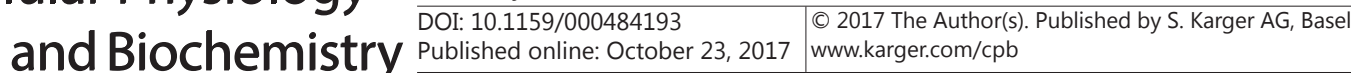 \\ Zong et al.: Cannabinoids Affect Retinal Capillaries}

\section{Retinal $C B_{1}$ expression}

Western blotting of the whole retina or retinal vessels is shown in Fig. 6A, B. The band corresponding to $\mathrm{CB}_{1}$ in the whole retina was significantly more intense than the band corresponding to the retinal vessels (whole retina/vessel ratio $=1 / 0.26 \pm 0.07, P<0.01$ ). Quantitative PCR was also performed to determine the relative abundance of $\mathrm{CB}_{1}$ mRNA in the whole retina and retinal vessels. As shown in Fig. $6 \mathrm{C}, \mathrm{CB}_{1}$ mRNA expression was relatively low in the retinal vessels, but was much greater in the whole retina (whole retina/vessel ratio $=1 / 0.21 \pm 0.03, P<0.01$ ). Immunohistochemical labeling also showed that $\mathrm{CB}_{1}$ was predominantly expressed on the retinal ganglion cells and on the ganglion cell axons rather than on the microvasculature (Fig. 6D, E).

\section{Discussion}

This is the first study to use a whole-mount perfused retinal capillary model to explore the effects of cannabinoids on retinal capillaries and the possible mechanisms in the rat. This effect of cannabinoids was mediated by $\mathrm{CB}_{1}$, which is involved the NO-guanylate cyclase signaling system, and required an intact endothelium.

Both endocannabinoids 2-AG and AEA and the exogenous cannabinoid R-(+)WIN55212-2 exerted a vasorelaxation effect on NA-precontracted capillaries. The $\mathrm{EC}_{50}$ values for 2-AG, AEA, and R-(+)-WIN55212-2 were almost equal, whereas R-(+)-WIN55212-2 induced more obvious vasorelaxation in the retinal capillaries than 2-AG or AEA at the same concentration. The vasorelaxant signaling system used by anandamide and 2-AG has been extensively investigated in different vascular beds [5, 26, 30, 31], but few previous studies have undertaken to clarify the vasomechanism of R-(+)-WIN55212-2. For these two reasons, the vasorelaxant signal system of R-(+)-WIN55212-2 was mainly investigated in our subsequent experiments.

Previous studies have examined the regulatory effects of cannabinoids on vessel tone [8, $16,32]$, although these studies focused on arteries, arterioles or isolated vessels. However, there has been no direct evidence that cannabinoids affect capillaries or pericytes. In part, this may be attributable to the difficulty of visualizing living capillaries and pericytes. In our study, we used a whole-mount perfused model and IR-DIC microscopy, which showed the diastolic activity of pericytes and capillaries mediated by R-(+)-WIN55212-2 in real time. Contraction or relaxation of the capillaries was associated with corresponding changes in the pericyte morphology. The changes in the capillary diameter induced by NA or R-(+)WIN55212-2 at pericyte soma sites was greater than the changes at the non-pericyte sites. The change in the capillary diameter was significantly positively correlated with the change in pericyte width. These results suggest that cannabinoids alter vessel activity via pericytes, contractile cells that regulate the retinal capillaries.

R-(+)-WIN55212-2 did not promote vasorelaxation in the absence of NA (basal tone) in non-pretreated capillaries. However, it exerted a stable vasodilatory effect on NAprecontracted capillaries. It was proposed that this effect was partly due to the weaker spontaneous tone of ex vivo retinal vessels [33] which were also found in other studies [26, 34].

The pharmacological effects of cannabinoids are predominantly mediated by $\mathrm{CB}_{1}$, $\mathrm{CB}_{2}$, or $\mathrm{CB}_{\mathrm{e}}[15,16,35-39]$. In our study, we have shown that R-(+)-WIN55212-2-induced vasorelaxation was suppressed by two $\mathrm{CB}_{1}$ antagonists, but not by a $\mathrm{CB}_{2}$ antagonist. These findings are consistent with the results of studies using bovine ophthalmic arteries and mesenteric arterioles, in which cannabinoids mediated vasorelaxation via $\mathrm{CB}_{1}$, whereas $\mathrm{CB}_{2}$ was not involved $[17,40]$. Although several studies have demonstrated that $\mathrm{CB}_{\mathrm{e}}$ is involved in cannabinoid-induced vasodilation via an endothelium-dependent signaling mechanism $[16,41]$, this may be attributable to the different cannabinoids or species used in those studies. However, using an isolated retinal vessel model, MacIntyre et al. reported that neither R-(+)-WIN55212-2 nor the $\mathrm{CB}_{1}$-selective agonist arachidonyl-2-chloroethylamide caused the dilation of precontracted retinal microvessels [16]. These different results might 
be explained as follows. Isolated retinal arterioles were used in their study, whereas we used a whole-mount retinal model. Previous studies have shown that $\mathrm{CB}_{1}$ is expressed in several retinal layers [10], but it is unknown whether $\mathrm{CB}_{1}$ is expressed on retinal arterioles. Using quantitative PCR and western blotting, we detected relatively low $\mathrm{CB}_{1}$ mRNA and $\mathrm{CB}_{1}$ protein expression in the retinal vessels, and immunohistochemical labeling showed that the $\mathrm{CB}_{1}$ receptor was primarily located on retinal ganglion cells and ganglion cell axons, rather than on the microvasculature. This suggests that R-(+)-WIN55212-2 did not evoke a vessel response in MacIntyre's studies because of the expression of $\mathrm{CB}_{1}$ on retinal vessels is low.

The relatively high expression of $\mathrm{CB}_{1}$ observed on neurons suggests that cannabinoids may affect the retinal capillary indirectly, through the retinal neurovascular unit, which was first mentioned by Hawkins et al. [42]. They first considered that the cerebral microvascular endothelium, together with astrocytes, pericytes, neurons, and the extracellular matrix, formed a complex functional unit. Zygmunt et al. [22] reported that AEA activated the vanilloid receptors on the primary sensory neurons, and dilated the rat hepatic arteries and guinea-pig basilar arteries. Consistent with former reports, our findings also suggest the existence of an immediate link between neurons and vascular regulation. Because the whole-mount retina includes vessels and neurons, it may be a better ex vivo model in which to investigate the regulation of retinal vessels.

We also found that the R-(+)-WIN55212-2-induced vasorelaxation of rat retinal capillaries was inhibited by endothelial denudation. Similar to our results, a prior study using rat aorta [32] showed that R-(+)-WIN55212-2-induced vasorelaxation was dependent on the presence of an intact end othelium. Er-Ning Su et al. also highlighted the critical role of the endothelium in cannabinoid-induced vasoactivity in isolated perfused retinal arterioles [15]. However, other studies have suggested that R-(+)-WIN55212-2-induced relaxation is endothelium independent in other vessels, including the rat small mesenteric artery [43] and gracilis arterioles [21]. Interestingly, using the bovine ophthalmic artery, Romano et al. demonstrated that both endothelium-dependent and -independent pathways are involved in cannabinoid-agonist-induced relaxation [17]. The use of different vessels might explain the inconsistent results of these studies.

In our study, R-(+)-WIN55212-2-induced vasorelaxation was endothelium dependent. For this reason, a more detailed endothelial vasorelaxant pathway was investigated, using NO-cGMP or vaosactive prostanoid inhibitors. Pretreatment with the NOS inhibitor L-NAME almost completely inhibited R-(+)-WIN55212-2-induced vasorelaxation of the rat retinal capillaries. This is consistent with previous reports that endothelium-derived factors, such as NO, are involved in the cannabinoid-receptor-mediated vasorelaxation of bovine ophthalmic arteries [17] and rabbit aortic rings [31]. The guanylyl cyclase inhibitor ODQ had a similar effect, and a previous study has reported that cannabinoids induced the phosphorylation of endothelial NOS and consequently activated guanylyl cyclase to generate cGMP [44, 45], which supports our findings. In contrast, indomethacin, a COX inhibitor, did not alter the effects of R-(+)-WIN55212-2. Although previous studies have demonstrated that R-(+)-WIN55212-2 activates the COX pathway [46], to the best of our knowledge, no study has shown that R-(+)-WIN55212-2 induces vasodilation via the COX pathway, which is consistent with our result.

In this study, we studied the effects of cannabinoids on retinal capillaries in rats, but because the vascular pharmacological responses differ between species [33], the effects of cannabinoids in the human retina must still be explored. It would be interesting to examine the effects of cannabinoids using a primate retina. It is also unclear how the activation of $\mathrm{CB}_{1}$ is linked to the release of NO in the endothelium. Additional experiments should provide more insight into the underlying signaling pathway.

In summary, we have shown that cannabinoids are capable of dilating the pericytecontaining retinal capillaries in rats via an NO-cGMP signaling system, and that this effect appears to be mediated by $\mathrm{CB}_{1}$, which is mainly located on neurons. However, as the response to cannabinoids varies greatly between species, further studies with a primate model could clarify the role of cannabinoids in vascular regulation in the human eye. 


\section{Cellular Physiology Cell Physiol Biochem 2017;43:2088-2101

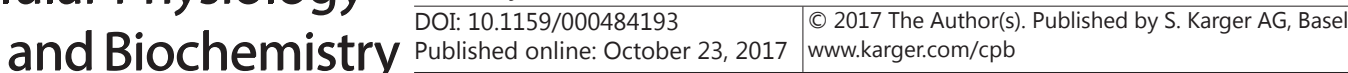 \\ Zong et al.: Cannabinoids Affect Retinal Capillaries}

Regardless of which mechanism is involved, the ability of cannabinoids to dilate the retinal capillaries may have therapeutic implications for retinal vascular diseases, and the $\mathrm{CB}_{1}$ receptor may provide a new target for the regulation of the retinal blood flow.

\section{Acknowledgements}

Publication of this article was supported, in part, by research grants from the National Major Scientific Equipment Program (2012YQ12008003), the National Natural Science Foundation of China (NSFC grant 81400396), and the Shanghai Committee of Science and Technology (16140901000, 13430710500 and 15DZ1942204). The authors thank our colleagues who helped perform this study.

\section{Disclosure Statement}

None.

\section{References}

1 Burdyga T, Borysova L: Calcium signalling in pericytes. J Vasc Res 2014;51:190-199.

-2 Hall CN, Reynell C, Gesslein B, Hamilton NB, Mishra A, Sutherland BA, O'Farrell FM, Buchan AM, Lauritzen M, Attwell D: Capillary pericytes regulate cerebral blood flow in health and disease. Nature 2014;508:5560.

-3 Casey DP, Nichols WW, Conti CR, Braith RW: Relationship between endogenous concentrations of vasoactive substances and measures of peripheral vasodilator function in patients with coronary artery disease. Clin Exp Pharmacol Physiol 2010;37:24-28.

4 Newman EA: Functional hyperemia and mechanisms of neurovascular coupling in the retinal vasculature. J Cereb Blood Flow Metab 2013;33:1685-1695.

-5 Stanley CP, Hind WH, Tufarelli C, O'Sullivan SE: The endocannabinoid anandamide causes endotheliumdependent vasorelaxation in human mesenteric arteries. Pharmacol Res 2016;113:356-363.

-6 Stanley CP, O'Sullivan SE: Cyclooxygenase metabolism mediates vasorelaxation to 2-arachidonoylglycerol (2-AG) in human mesenteric arteries. Pharmacol Res 2014;81:74-82.

-7 Iring A, Ruisanchez E, Leszl-Ishiguro M, Horvath B, Benko R, Lacza Z, Jarai Z, Sandor P, Di Marzo V, Pacher P, Benyo Z: Role of endocannabinoids and cannabinoid-1 receptors in cerebrocortical blood flow regulation. PLoS One 2013;8:e53390.

-8 Baranowska-Kuczko M, MacLean MR, Kozlowska H, Malinowska B: Endothelium-dependent mechanisms of the vasodilatory effect of the endocannabinoid, anandamide, in the rat pulmonary artery. Pharmacol Res 2012;66:251-259.

-9 Schwitzer T, Schwan R, Angioi-Duprez K, Giersch A, Laprevote V: The Endocannabinoid System in the Retina: From Physiology to Practical and Therapeutic Applications. Neural Plast 2016;2016:2916732.

$\checkmark 10$ Bouchard JF, Casanova C, Cecyre B, Redmond WJ: Expression and Function of the Endocannabinoid System in the Retina and the Visual Brain. Neural Plast 2016;2016:9247057.

-11 Hochhauser E, Lahat E, Sultan M, Pappo 0, Waldman M, Sarne Y, Shainberg A, Gutman M, Safran M, Ben Ari Z: Ultra Low Dose Delta 9-Tetrahydrocannabinol Protects Mouse Liver from Ischemia Reperfusion Injury. Cell Physiol Biochem 2015;36:1971-1981.

12 Kokona D, Georgiou PC, Kounenidakis M, Kiagiadaki F, Thermos K: Endogenous and Synthetic Cannabinoids as Therapeutics in Retinal Disease. Neural Plast 2016;2016:8373020.

-13 Miller S, Leishman E, Hu SS, Elghouche A, Daily L, Murataeva N, Bradshaw H, Straiker A: Harnessing the Endocannabinoid 2-Arachidonoylglycerol to Lower Intraocular Pressure in a Murine Model. Invest Ophthalmol Vis Sci 2016;57:3287-3296. 


\section{Cellular Physiology Cell Physiol Biochem 2017;43:2088-2101 \begin{tabular}{l|l|l|l|l}
\hline DOI: 10.1159/000484193 2017 The Author(s). Published by S. Karger AG, Basel \\
\hline
\end{tabular} and Biochemistry Published online: October 23, 2017 www.karger.com/cpb}

Zong et al.: Cannabinoids Affect Retinal Capillaries

14 Nucci C, Gasperi V, Tartaglione R, Cerulli A, Terrinoni A, Bari M, De Simone C, Agro AF, Morrone LA, Corasaniti MT, Bagetta G, Maccarrone M: Involvement of the endocannabinoid system in retinal damage after high intraocular pressure-induced ischemia in rats. Invest Ophthalmol Vis Sci 2007;48:2997-3004.

-15 Su EN, Kelly ME, Cringle SJ, Yu DY: Role of Endothelium in Abnormal Cannabidiol-Induced Vasoactivity in Retinal Arterioles. Invest Ophthalmol Vis Sci 2015;56:4029-4037.

-16 MacIntyre J, Dong A, Straiker A, Zhu J, Howlett SE, Bagher A, Denovan-Wright E, Yu DY, Kelly ME: Cannabinoid and lipid-mediated vasorelaxation in retinal microvasculature. Eur J Pharmacol 2014;735:105-114.

17 Romano MR, Lograno MD: Cannabinoid agonists induce relaxation in the bovine ophthalmic artery: evidences for CB1 receptors, nitric oxide and potassium channels. Br J Pharmacol 2006;147:917-925.

18 Peppiatt CM, Howarth C, Mobbs P, Attwell D: Bidirectional control of CNS capillary diameter by pericytes. Nature 2006;443:700-704.

19 Fernandez-Klett F, Offenhauser N, Dirnagl U, Priller J, Lindauer U: Pericytes in capillaries are contractile in vivo, but arterioles mediate functional hyperemia in the mouse brain. Proc Natl Acad Sci U S A 2010;107:22290-22295.

20 Zhang Q, Meng Z: The vasodilator mechanism of sulfur dioxide on isolated aortic rings of rats: Involvement of the K+ and Ca2+ channels. Eur J Pharmacol 2009;602:117-123.

21 Szekeres M, Nadasy GL, Turu G, Soltesz-Katona E, Toth ZE, Balla A, Catt KJ, Hunyady L: Angiotensin II induces vascular endocannabinoid release, which attenuates its vasoconstrictor effect via CB1 cannabinoid receptors. J Biol Chem 2012;287:31540-31550.

22 Zygmunt PM, Petersson J, Andersson DA, Chuang H, Sorgard M, Di Marzo V, Julius D, Hogestatt ED: Vanilloid receptors on sensory nerves mediate the vasodilator action of anandamide. Nature 1999;400:452-457.

23 Matsushita K, Puro DG: Topographical heterogeneity of K(IR) currents in pericyte-containing microvessels of the rat retina: effect of diabetes. J Physiol 2006;573:483-495.

24 Gao F, Li T, Hu J, Zhou X, Wu J, Wu Q: Comparative analysis of three purification protocols for retinal ganglion cells from rat. Mol Vis 2016;22:387-400.

25 Wu HM, Yang YM, Kim SG: Rimonabant, a cannabinoid receptor type 1 inverse agonist, inhibits hepatocyte lipogenesis by activating liver kinase B1 and AMP-activated protein kinase axis downstream of Galpha i/o inhibition. Mol Pharmacol 2011;80:859-869.

26 Baranowska-Kuczko M, Kozlowska H, Kozlowski M, Schlicker E, Kloza M, Surazynski A, Grzeda E, Malinowska B: Mechanisms of endothelium-dependent relaxation evoked by anandamide in isolated human pulmonary arteries. Naunyn Schmiedebergs Arch Pharmacol 2014;387:477-486.

27 Tham CS, Whitaker J, Luo L, Webb M: Inhibition of microglial fatty acid amide hydrolase modulates LPS stimulated release of inflammatory mediators. FEBS Lett 2007;581:2899-2904.

28 Gim H, Nam JH, Lee S, Shim JH, Kim HJ, Ha KT, Kim BJ: Quercetin Inhibits Pacemaker Potentials via Nitric Oxide/cGMP-Dependent Activation and TRPM7/ANO1 Channels in Cultured Interstitial Cells of Cajal from Mouse Small Intestine. Cell Physiol Biochem 2015;35:2422-2436.

29 Bendhack LM, Bonaventura D, de Lima RG, Silva RSd: Mechanisms underlying relaxation induced by a new nitric oxide donor. The FASEB Journal 2006;20:A1126.

-30 Gauthier KM, Baewer DV, Hittner S, Hillard CJ, Nithipatikom K, Reddy DS, Falck JR, Campbell WB: Endothelium-derived 2-arachidonylglycerol: an intermediate in vasodilatory eicosanoid release in bovine coronary arteries. Am J Physiol Heart Circ Physiol 2005;288:H1344-1351.

-31 Mukhopadhyay S, Chapnick BM, Howlett AC: Anandamide-induced vasorelaxation in rabbit aortic rings has two components: G protein dependent and independent. Am J Physiol Heart Circ Physiol 2002;282:H20462054.

-32 Dannert MT, Alsasua A, Herradon E, Martin MI, Lopez-Miranda V: Vasorelaxant effect of Win 55, 212-2 in rat aorta: new mechanisms involved. Vascul Pharmacol 2007;46:16-23.

-33 Elhusseiny A, Hamel E: Muscarinic--but not nicotinic--acetylcholine receptors mediate a nitric oxidedependent dilation in brain cortical arterioles: a possible role for the M5 receptor subtype. J Cereb Blood Flow Metab 2000;20:298-305.

-34 Bek T, Holmgaard K: GABA-induced relaxation of porcine retinal arterioles in vitro depends on inhibition from the perivascular retina and is mediated by GABAC receptors. Invest Ophthalmol Vis Sci 2012;53:33093315 . 


\section{Cellular Physiology Cell Physiol Biochem 2017;43:2088-2101 \begin{tabular}{l|l|l} 
DOI: 10.1159/000484193 & $\begin{array}{l}\text { O 2017 The Author(s). Published by S. Karger AG, Basel } \\
\text { www.karger.com/cpb }\end{array}$ \\
\hline
\end{tabular}}

Zong et al.: Cannabinoids Affect Retinal Capillaries

-35 Pacher P, Kunos G: Modulating the endocannabinoid system in human health and disease--successes and failures. FEBS J 2013;280:1918-1943.

-36 Di Marzo V: The endocannabinoid system: its general strategy of action, tools for its pharmacological manipulation and potential therapeutic exploitation. Pharmacol Res 2009;60:77-84.

37 Zhang X, Gao S, Niu J, Li P, Deng J, Xu S, Wang Z, Wang W, Kong D, Li C: Cannabinoid 2 Receptor Agonist Improves Systemic Sensitivity to Insulin in High-Fat Diet/Streptozotocin-Induced Diabetic Mice. Cell Physiol Biochem 2016;40:1175-1185.

-38 Li X, Han D, Tian Z, Gao B, Fan M, Li C, Li X, Wang Y, Ma S, Cao F: Activation of Cannabinoid Receptor Type II by AM1241 Ameliorates Myocardial Fibrosis via Nrf2-Mediated Inhibition of TGF-beta1/Smad3 Pathway in Myocardial Infarction Mice. Cell Physiol Biochem 2016;39:1521-1536.

-39 Jenkin KA, McAinch AJ, Briffa JF, Zhang Y, Kelly DJ, Pollock CA, Poronnik P, Hryciw DH: Cannabinoid receptor 2 expression in human proximal tubule cells is regulated by albumin independent of ERK1/2 signaling. Cell Physiol Biochem 2013;32:1309-1319.

40 Stanley CP, Hind WH, Tufarelli C, O'Sullivan SE: Cannabidiol causes endothelium-dependent vasorelaxation of human mesenteric arteries via CB1 activation. Cardiovasc Res 2015;107:568-578.

41 Jarai Z, Wagner JA, Varga K, Lake KD, Compton DR, Martin BR, Zimmer AM, Bonner TI, Buckley NE, Mezey E, Razdan RK, Zimmer A, Kunos G: Cannabinoid-induced mesenteric vasodilation through an endothelial site distinct from CB1 or CB2 receptors. Proc Natl Acad Sci U S A 1999;96:14136-14141.

42 Hawkins BT, Davis TP: The blood-brain barrier/neurovascular unit in health and disease. Pharmacol Rev 2005;57:173-185.

43 Ho WS, Hiley CR: Endothelium-independent relaxation to cannabinoids in rat-isolated mesenteric artery and role of Ca2+ influx. Br J Pharmacol 2003;139:585-597.

-44 Deutsch DG, Goligorsky MS, Schmid PC, Krebsbach RJ, Schmid HH, Das SK, Dey SK, Arreaza G, Thorup C, Stefano G, Moore LC: Production and physiological actions of anandamide in the vasculature of the rat kidney. J Clin Invest 1997;100:1538-1546.

45 Maccarrone M, Bari M, Lorenzon T, Bisogno T, Di Marzo V, Finazzi-Agro A: Anandamide uptake by human endothelial cells and its regulation by nitric oxide. J Biol Chem 2000;275:13484-13492.

46 Mestre L, Correa F, Docagne F, Clemente D, Guaza C: The synthetic cannabinoid WIN 55, 212-2 increases COX-2 expression and PGE2 release in murine brain-derived endothelial cells following Theiler's virus infection. Biochem Pharmacol 2006;72:869-880. 